\title{
In Pursuit of an Effective Treatment: the Past, Present and Future of Clinical Trials in Inclusion Body Myositis
}

\author{
A. M. Snedden, MRCP, MSC ${ }^{1,2}$ \\ J. B. Lilleker, $M R C P, P h D^{1,2}$ \\ H. Chinoy, FRCP PhD ${ }^{1,3,4, *}$
}

\begin{abstract}
Address
*,1 Centre for Musculoskeletal Research, Faculty of Biology, Medicine and Health, The University of Manchester, 2nd floor, Stopford Building, Oxford Road, Manchester, M13 9PT, UK

Email: hector.chinoy@manchester.ac.uk

${ }^{2}$ Manchester Centre for Clinical Neurosciences, Salford Royal NHS Foundation Trust, Manchester Academic Health Science Centre, Salford, UK

${ }^{3}$ National Institute for Health Research Manchester Biomedical Research Centre, Manchester University NHS Foundation Trust, The University of Manchester, Manchester, UK

${ }^{4}$ Department of Rheumatology, Salford Royal NHS Foundation Trust, Manchester Academic Health Science Centre, Salford, UK
\end{abstract}

Published online: 9 February 2021

(C) The Author(s) 2021

This article is part of the Topical Collection on Inflammatory Myopathies and Sjogren's

Keywords Inclusion body myositis - Clinical trial · Immunosuppression · Protein homeostasis · Inflammatory myopathy

\section{Abstract}

Purpose of review No clinical trial in sporadic inclusion body myositis (IBM) thus far has shown a clear and sustained therapeutic effect. We review previous trial methodology, explore why results have not translated into clinical practice, and suggest improvements for future IBM trials.

Recent findings Early trials primarily assessed immunosuppressive medications, with no significant clinical responses observed. Many of these studies had methodological issues, including small participant numbers, nonspecific diagnostic criteria, short treatment and/ or assessment periods and insensitive outcome measures. Most recent IBM trials have instead focused on nonimmunosuppressive therapies, but there is mounting evidence supporting a primary autoimmune aetiology, including the discovery of immunosuppression-resistant clones of cytotoxic T cells and anti-CN-1A autoantibodies which could potentially be used to stratify patients into different cohorts. The latest trials 
have had mixed results. For example, bimagrumab, a myostatin blocker, did not affect the 6-min timed walk distance, whereas sirolimus, a promotor of autophagy, did. Larger studies are planned to evaluate the efficacy of sirolimus and arimoclomol.

Summary Thus far, no treatment for IBM has demonstrated a definite therapeutic effect, and effective treatment options in clinical practice are lacking. Trial design and ineffective therapies are likely to have contributed to these failures. Identification of potential therapeutic targets should be followed by future studies using a stratified approach and sensitive and relevant outcome measures.

\section{Introduction}

Sporadic inclusion body myositis (IBM) is a progressive muscle disorder characterised by the presence of both inflammatory and degenerative pathological features. Typical features on muscle biopsy include CD8+ T cell inflammatory infiltrates, rimmed vacuoles, inclusion bodies and mitochondrial abnormalities [1]. Unlike other idiopathic inflammatory myopathies (IIM), patients with IBM do not improve in response to immunosuppression, with muscle weakness progressing and culminating in significant disability.
Numerous potential IBM therapies have been assessed in observational studies and clinical trials. Here, we review these studies and assess their methodology to determine why they were unsuccessful with no ensuing change in clinical practice. Using these insights and recent advances in our understanding of IBM pathology and natural history, we then shape recommendations for future clinical trials.

\section{Clinical trials in IBM}

Relevant studies were selected from the results of a MEDLINE and Pubmed search, performed using the key words "Inclusion body myositis" and "Clinical trial" or "trial". We grouped the studies by type of intervention studied (listed in Table 1).

Conventional immunosuppressive therapies

\section{Prednisolone, azathioprine and methotrexate}

Most trials in IBM have focussed on immunosuppression. An early observational study performed in 1993 assessed the probability of clinical response to immunosuppression in IIM, including IBM as classified by Whitaker [4, 28]. Oral prednisolone $0.75 \mathrm{mg} / \mathrm{kg} /$ day was administered to 14 IBM patients, with clinical response assessed by muscle strength and laboratory investigations including serum total creatine kinase (CK). After a minimum of four weeks, eight demonstrated "partial clinical response" and six had "no response". Ten patients were additionally administered at least $5 \mathrm{mg} /$ week of oral methotrexate for a minimum of eight weeks, with six not responding, and four having "partial response". CK response was not specifically reported for the IBM patients. Whilst there appears to be a positive signal, the trial was unblinded, short duration, and mostly used subjective outcome measures. 


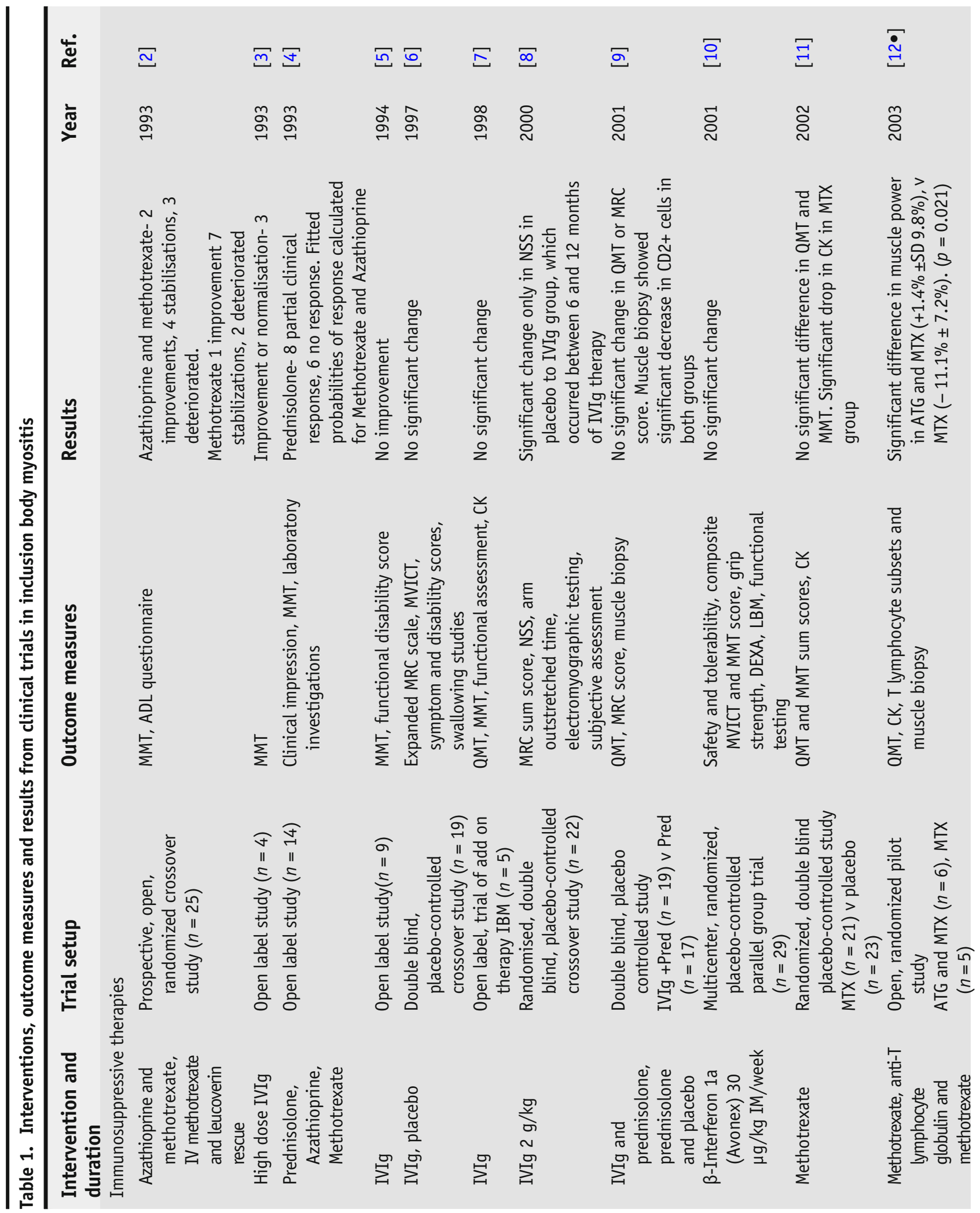




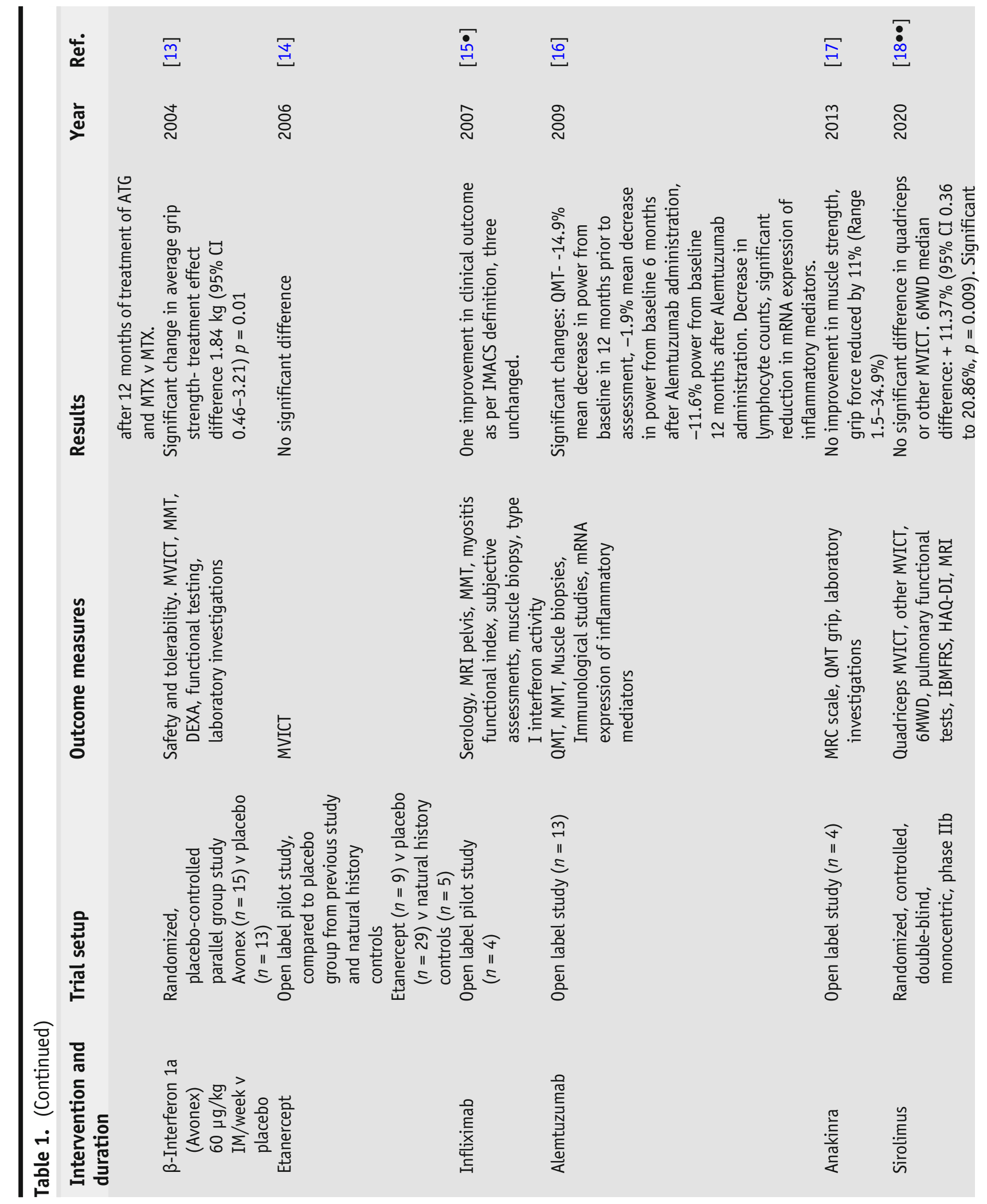



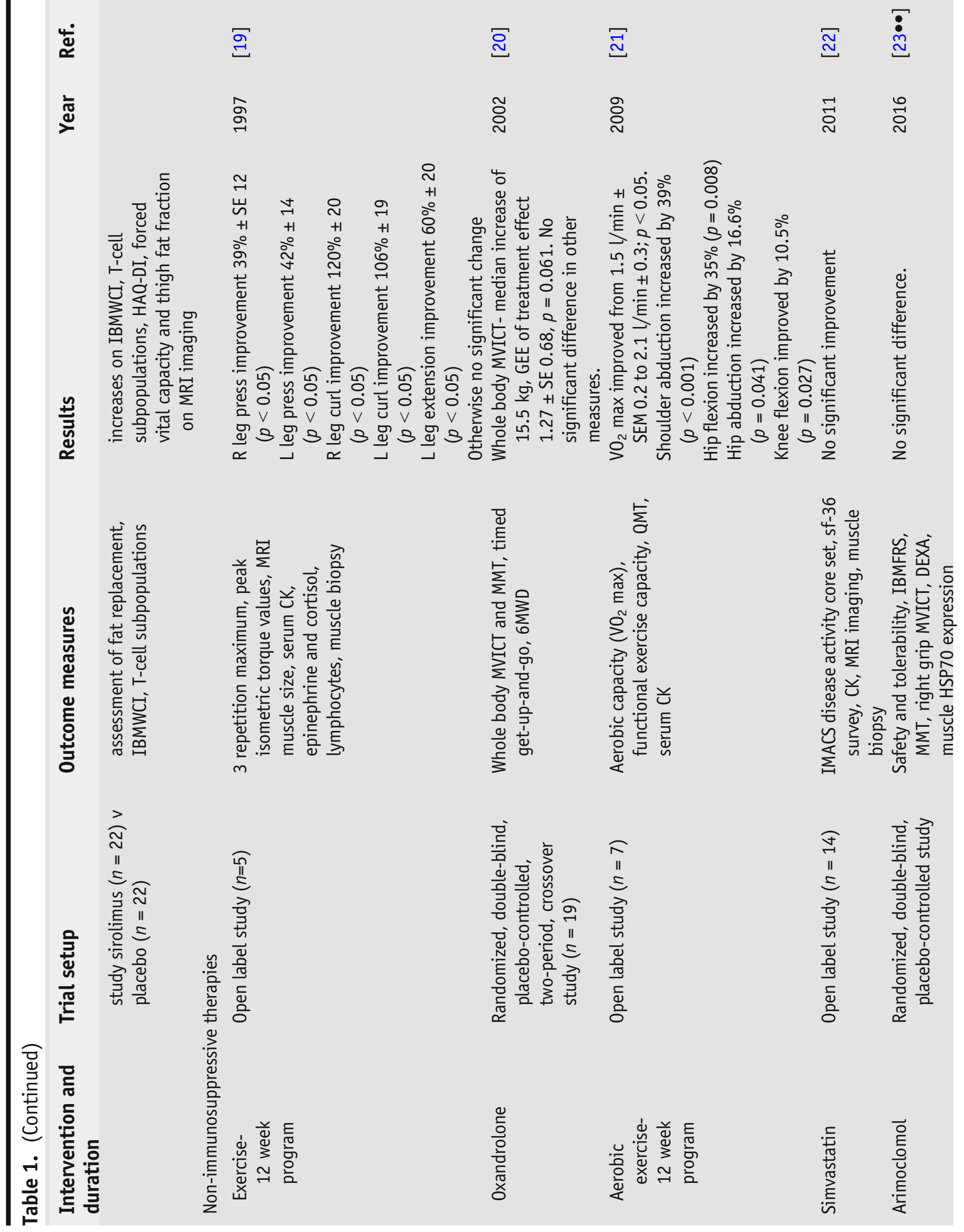


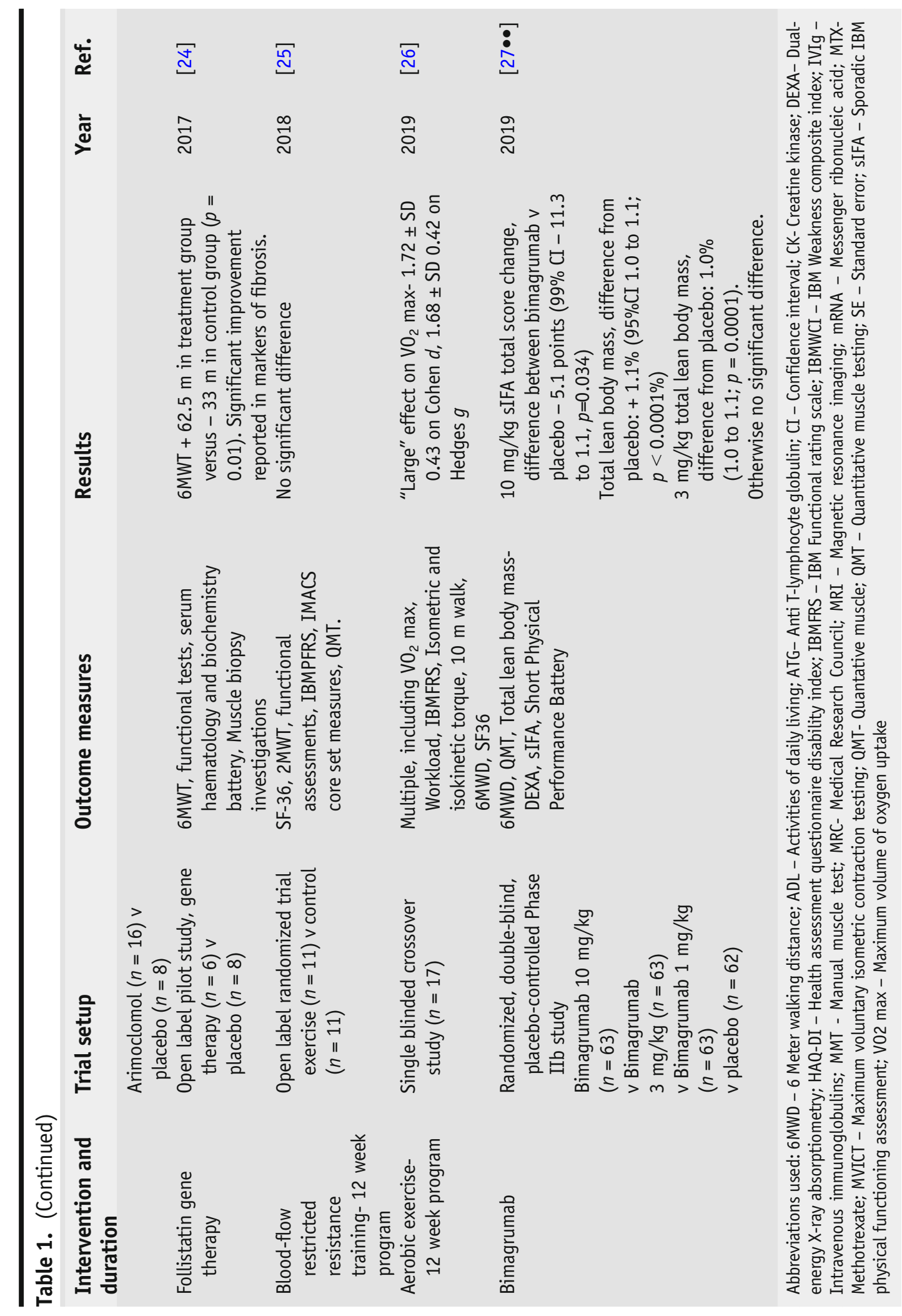


A prospective crossover trial by Leff et al. [2] from 1993 enrolled 11 IBM patients who did not respond to prednisolone. Participants were treated with either combination of oral azathioprine (up to $0.3 \mathrm{mg} / \mathrm{kg} /$ day) and methotrexate (up to $0.3 \mathrm{mg} / \mathrm{kg} /$ week), or weekly intravenous (IV) methotrexate (up to $0.5 \mathrm{~g} / \mathrm{m}^{2}$ ) and leucovorin rescue for 6 months [2]. No significant difference was reported in the manual muscle test (MMT) or activities of daily living (ADLs) questionnaire post-treatment. All three patients with $\mathrm{CK}>1000$ exhibited some improvement in MMT and ADL scores, compared to none with $\mathrm{CK}<1000$. A pretreatment muscle biopsy demonstrating $\geq 50$ mononuclear cells in at least one focus was also associated with improvement on treatment.

Leff et al. [2] combined this study with a retrospective review of 25 IBM patients, which showed a reduction of $>40 \%$ or normalisation of CK in 21 of 24 patients treated with prednisolone, six of 13 treated with azathioprine, and 9 out of 10 treated with methotrexate. The authors hypothesised that IBM with a more active inflammatory component may have some response to immunosuppression. However, no significant clinical benefit was shown, potentially as numbers were small, patients and clinicians were unblinded, and clinical outcome measures subjective. These earlier studies used nonstandardized approaches for diagnosis, e.g. using Bohan and Peter criteria [29] and presence of rimmed vacuoles on muscle biopsy to diagnose IBM. The approach reflects practice at the time, but without including criterion referring to specific IBM weakness patterns, patients with genetic vacuolar myopathies or late IBM and irreversible muscle damage may have been included.

A larger randomized placebo-controlled trial with 44 patients comparing 5$20 \mathrm{mg} /$ week of methotrexate to placebo showed no significant clinical improvement in quantitative muscle testing (QMT) or MMT in the active treatment arm after 22 or 48 weeks [11]. Mean CK levels dropped significantly in the methotrexate compared to control group (676-274 for methotrexate; 725-690 for placebo; $95 \% \mathrm{CI}-732$ to $-102, p=0.01) 3$ months after treatment initiation. The observed improvement in CK without clinical response is consistent with findings from Leff et al. [2].

In this review QMT refers to assessments with protocols using a dynamometer. One of these protocols, maximum voluntary isometric contraction testing (MVICT), is specifically used in some trials.

\section{IV immunoglobulin and anti-T lymphocyte globulin}

A double blind, placebo-controlled crossover study from 1997 using $2 \mathrm{~g} / \mathrm{kg}$ of IV immunoglobulin (IVIg) for three months showed a nonsignificant trend towards strength increase, measured by total Medical Research Council (MRC) scale (mean change postIVIg +4.2 ; range -16 to +39.8 versus -2.7 postplacebo; range -10 to $+8 ; p<0.1$ ) [6]. A similar finding was noted in MVICT, a form of QMT. Some assessments of swallowing speed also significantly improved. A further similar crossover study from 2000 involving 22 patients with IBM reported no disease progression in $90 \%$ of patients after $2 \mathrm{~g} / \mathrm{kg}$ IVIg monthly for 6 months, and no significant improvement in MRC sum score [8]. A small but significant improvement in the neuromuscular symptom score (NSS) was found after 6 months $(+6.2$ points IVIg versus +1.2 points placebo, $p<$ $0.05)$. When the groups crossed over, there was +2.6 improvement after 
6 months of IVIg versus -0.6 points after placebo $(p<0.05)$. Whilst these trials had a double-blind design, a potential confounder is that 16 of 19 patients in the first crossover study correctly guessed when they received IVIg [6].

In 2001, Dalakas et al. [9] also assessed the effect of IVIg combined with prednisolone in IBM in a double-blind, placebo-controlled study of 36 patients. All patients were treated a tapering dose of prednisolone for four weeks starting at $60 \mathrm{mg}$ daily. Shortly after starting prednisolone, the first of three doses of $2 \mathrm{~g} / \mathrm{kg}$ of IVIg or placebo was administered over 2 days every month for 3 months. No significant differences were noted in total MRC scores or on QMT total scores between groups or at baseline. Postintervention, muscle biopsies were performed in 24 patients from both groups and compared to earlier biopsies. The number of $\mathrm{CD} 2+$ cells/myofiber and foci of endomysial inflammation decreased in both groups, with a further significant decrease in the IVIg group compared to placebo. The findings suggest a decrease in markers of inflammation following immunosuppression and an additive effect of IVIg, but did not translate to clinical benefit according to the trial measures. It is likely that a decrease in inflammation will not result in immediate recovery of skeletal muscle, and the short trial period would make any effect difficult to detect. Due to an absence of clear clinical efficacy, a small risk of immune reaction or thrombus, and limited availability, most clinicians do not routinely use IVIg for IBM.

Anti-T lymphocyte globulins (ATG), animal-derived antibodies against human T cells, were administered to IBM patients in addition to methotrexate, in a small, open label, randomized study in 2003, with an ATG and oral methotrexate group $(n=11)$ compared to oral methotrexate alone $(n=5)$ over 12 months[12•]. Outcome measures included QMT of various muscle groups, and an open muscle biopsy immediately before and after treatment. Overall mean muscle strength increased in the ATG and methotrexate group by $1.4 \%$ $(S D \pm 9.8)$, whereas in those treated with methotrexate alone there was $11.1 \%$ decrease ( $S D \pm 7.2, p=0.021$ ). No significant changes in inflammation were reported in repeat muscle biopsies. The positive result is surprising considering that mean muscle strength was greater after a year, despite one course of ATG being administered. Given the open label nature of the study, the findings could perhaps represent a placebo response, or alternatively, there may have been a therapeutic effect which would require a larger confirmatory randomized controlled trial.

\section{Cytokines and cytokine receptor inhibitors}

\section{$\beta$-Interferon 1a}

$\beta$-Interferon 1a is an anti-inflammatory cytokine used to treat multiple sclerosis, and was assessed in a randomized, double-blind, placebo-controlled trial involving 30 IBM patients in 2001 [10]. Sixteen participants were randomized to receive $30 \mu \mathrm{g}$ of $\beta$-Interferon 1a subcutaneously and fourteen to receive placebo for 24 weeks. The primary outcome measures were safety and tolerability. Efficacy was also assessed using composite MMT and MVICT, including assessment of grip strength, two upper and three lower limb muscle groups, muscle mass estimation by dual-energy X-ray absorptiometry (DEXA), and functional tests. No significant improvement was observed in the secondary 
endpoints (e.g. mean change in composite MVICT score $-0.16 \mathrm{~kg}$ [SD \pm 0.64 ] for placebo versus $-0.26 \mathrm{~kg}[S D \pm 0.69]$ for the $\beta$-Interferon $1 \mathrm{a}, p=0.66$ ).

The study was later replicated using a higher dose of $60 \mu \mathrm{g} \beta$-interferon $1 \mathrm{a}$ [13]. Here, mean grip MVICT significantly improved from baseline to week 24 by $0.23 \mathrm{~kg}$ (SD 1.66) in the $\beta$-interferon 1a group compared to a $1.45 \mathrm{~kg}$ (SD 1.44 ) decrease in the placebo group (treatment effect $1.84,95 \% \mathrm{CI} 0.46-3.21, p$ $=0.01)$. Otherwise, there was no significant difference in other outcome measures, including $\mathrm{CK}$ and functional assessments. The improvement in grip MVICT was not evident in the composite MMT and MVIC scores, possibly because these measures included strength measures of muscle groups less affected in IBM.

\section{TNF inhibition}

Etanercept, a tumour necrosis factor alpha (TNF $\alpha$ ) receptor fusion protein, binds and inactivates TNF $\alpha$ thus preventing proinflammatory effects [30], and is an established treatment for a number of conditions including psoriasis and rheumatoid arthritis [31]. In an open label study, nine IBM patients were treated with etanercept and outcomes compared to 29 controls from the previous $\beta$-interferon 1a studies [10,13], and a second group of five IBM patients who underwent MVICT as part of clinic follow-up [14]. No significant difference was noted in MVICT composite score, but a small, significant increase in grip strength was seen after 12 months of etanercept compared to natural history controls (etanercept + $0.19 \mathrm{~kg}[\mathrm{SD} \pm 1.8]$ versus placebo $-7.78 \mathrm{~kg}[\mathrm{SD} \pm 6.0], p=0.012)$.

Infliximab is a chimeric monoclonal antibody which exerts an anti-inflammatory effect by neutralising TNF $\alpha$, and is licenced for a number of diseases including rheumatoid arthritis, psoriasis, and inflammatory bowel disease. In an open label trial, infliximab was administered to 13 IIM patients (polymyositis $[n=5]$, dermatomyositis $[n=4]$, IBM $[n=4])[15 \bullet]$. The primary outcome measure was muscle Functional Index (FI) [32], and secondary clinical outcomes included MMT, serum biochemistry and subjective assessments. Overall, no significant improvement in FI was noted, although one IBM patient met the International Myositis Assessment and Clinical Studies (IMACS) definition of improvement [33].

\section{Anakinra}

Interleukin $1 \mathrm{~b}$ (IL1 $\beta$ ) is upregulated in IBM muscle fibres and promotes $\beta$ amyloid deposition in vitro [34]. Anakinra, an IL1 receptor antagonist [35], was assessed for therapeutic effects in an open label pilot study of four IBM patients treated for a mean period of 7.7 months [17]. No improvement in muscle strength, including grip, was noted after treatment.

\section{Alemtuzumab}

Alemtuzumab is a monoclonal antibody specific for CD52 found on lymphocytes, and is effective in the treatment of chronic lymphocytic leukaemia [36] and multiple sclerosis [37]. As IBM involves infiltration of cytotoxic CD52+ T cells, a prospective open label study was undertaken in 13 patients [16]. Natural history data prior to enrolment were taken from QMT assessments in the prior 12 months and 24 months for MMT. Muscle biopsy was performed at baseline 
and four doses of alemtuzumab and IV methylprednisolone administered. QMT measurements declined by $14.9 \%$ in the 12-month observational period prior to treatment. Six months post-alemtuzumab administration, there was a $13 \%$ improvement in mean QMT (ANOVA F $(1,12)=16.53, p<0.002)$. However by 12 months, QMT measurements dropped again by a mean of $11.6 \%$ from baseline $(p<0.01)$. MMT showed similar findings.

As expected, the total lymphocyte count dropped a week after alemtuzumab administration, so that at 6 months it was $30 \%$ of baseline, and $50 \%$ at 12 months. CD45RA+ CD62L- effector memory T lymphocytes were almost fully depleted after a week, but after 3 months numbers rebounded above baseline. In contrast, central memory $\mathrm{T}$ lymphocytes reached a nadir 3 months post-alemtuzumab but returned to baseline levels by 8 months. These findings may be significant as clones of highly differentiated killer cell lectin-like receptor G1 (KLRG1) positive cytotoxic T cells have been found in muscle from IBM patients [38]. Whilst conventional immunosuppression (e.g. prednisolone) does not affect their numbers, the transient decrease in lymphocytes induced by alemtuzumab may explain the transient improvement in symptoms. The study was not blinded or controlled, so attribution of clinical benefits to alemtuzumab treatment cannot be confirmed.

\section{Sirolimus (rapamycin)}

Sirolimus, also known as rapamycin, is a macrolide compound which promotes autophagy and inhibits lymphocyte activity by reducing sensitivity to IL-2 through inhibition of the mammalian target of rapamycin (mTOR) pathway [39]. A phase IIb randomized, double-blind placebo-

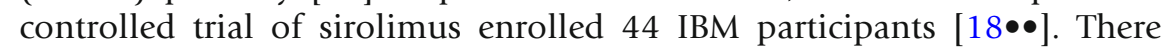
was no significant difference in quadriceps MVICT, the primary endpoint, between groups (median difference 3.78\%, 95\%CI -10.61 to $17.31, p=0.85$ ), or other outcome measures including the IBM Functional Rating Scale (IBMFRS) and QMT in individual muscle groups. The percent change in 6-min walking distance (6MWD) was significantly increased in the intervention group compared to placebo (median difference $11.37 \%, 95 \% \mathrm{CI} 0.36$ to $20.86, p=0.009$ ). Other significantly improved outcome measures included Health Assessment Questionnaire Disability Index, forced vital capacity, and thigh fat fraction as assessed by quantitative magnetic resonance imaging (MRI). These mixed results provide some evidence for the efficacy of sirolimus, and a larger phase III study is planned.

Non-immunosuppressive therapies

The pathological features of IBM include endomysial inflammatory infiltrates but also rimmed vacuoles, protein accumulation, 15-18-nm filaments and cytochrome oxidase C negative fibres [40, 41]. Protein homeostasis is usually maintained by processes involving autophagy receptor and chaperone proteins such as p62 and heat shock proteins (HSP). In IBM, inflammation contributes to failure of these mechanisms leading to protein aggregation and mitochondrial dysfunction [42, 43]. Treatments that increase protein clearance, encourage muscle growth and inhibit atrophy have therefore been trialled. 
Arimoclomol augments the heat shock response by prolonging activation of heat shock factor 1, the main transcription factor for HSP expression [44], and

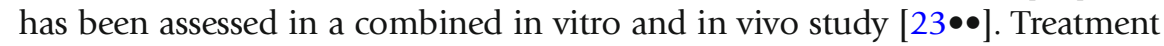
with arimoclomol significantly reduced the formation of cytoplasmic protein inclusions in cultured myocyte models of IBM and resulted in significantly greater grip strength in valosin-containing protein (VCP) mutation mice.

Arimoclomol was assessed in a double-blind, placebo-controlled phase II study of 24 patients with definite or probable sporadic IBM [23••] according to the Griggs criteria [1]. Patients were treated for 4 months and followed up for a further 8 months. Primary outcomes were safety and tolerability, and IBMFRS, MMT and MVICT also assessed as secondary outcomes. No significant difference in deterioration was observed in secondary outcome measures between groups, but there was a trend for reduced deterioration in the Arimoclomol group after 8 months (mean change in IBMFRS, $-0.68 \pm$ SD1.58 Arimoclomol versus $-2.50 \pm$ SD3.31 placebo, $p=0.055$; mean change in MMT $-0.12 \pm$ SD0.22 Arimoclomol versus $-0.26 \pm$ SD0.27 placebo, $p=0.147$ ).

Despite the positive preclinical studies, there was a trend for clinical improvement but no significant difference between intervention and placebo arms. There are several possible factors that might be involved: (a) the primary endpoint was safety, rather than efficacy; (b) whilst arimoclomol caused a reduction in inflammatory cells in the muscle biopsies, it is not a directly immunosuppressive medication. Therefore, inflammation will be ongoing in IBM patients after arimoclomol treatment, unlike in cell and mouse models where pathology is not directly caused by inflammation; (c) arimoclomol treatment lasted 4 months in the human trial, and for 10 months in the mouse trial, therefore the treatment may have been too short. A larger study is ongoing at the time of writing [45].

\section{Bimagrumab}

The RESILIENT study was a double-blind, placebo-controlled phase IIb study to assess the effects of bimagrumab $[27 \bullet \bullet]$, a human monoclonal antibody which targets type II A and B activin receptors, and thus preventing myostatin and activin from binding and exerting a negative regulatory function on muscle [46]. This study enrolled 251 IBM participants, randomized to receive $10 \mathrm{mg} / \mathrm{kg}, 3 \mathrm{mg} / \mathrm{kg}$, $1 \mathrm{mg} / \mathrm{kg}$ of bimagrumab or placebo. The antibody and placebo were administered every 4 weeks for 48 weeks. The primary outcome measure was the $6 \mathrm{MWD}$, with secondary outcomes being quadriceps QMT, total lean body mass as assessed by whole body DEXA, and the sporadic IBM Physical Functioning Assessment (sIFA) [47].

There was no significant difference between the bimagrumab groups and control groups in $6 \mathrm{MWD}$, with the bimagrumab $10 \mathrm{mg} / \mathrm{kg}$ group achieving a mean $10.6 \mathrm{~m}$ improvement from baseline ( $95 \% \mathrm{CI}$ : 12.9 to $30.2 \mathrm{~m}$ ) and a mean difference of $17.6 \mathrm{~m}$ from placebo ( $99 \% \mathrm{CI}$ : -19.6 to $54.8 \mathrm{~m} ; p=0.22$ ). The sIFA score was reduced by 5.1 points $(99 \% \mathrm{CI}-11.3$ to $1.1 ; p=0.034)$ in $t$, indicating a significant patient-reported improvement. Total lean body mass also showed a significant improvement after $10-\mathrm{mg} / \mathrm{kg}$ bimagrumab, being $102.8 \%$ of baseline mass (95\% CI: 101.4 to $104.2 \%)$, which is a $1.1 \%(95 \%$ 
CI: 1.0 to $1.1 \% ; p=0.001)$ difference from placebo. No significant improvement was seen in QMT of right quadriceps, Short Physical Performance Battery or falls rate.

A significant change in lean muscle mass was observed, confirming biological activity of the drug, and subjectively patients noted an improvement, but this did not translate to objective improvement. Although a pilot study with 14 patients showed a significant increase in 6MWD [48] $(14.6 \%, p<0.008$; analysis of covariance), the authors and others [49] have stated that 6MWD might not have been the most appropriate choice of primary endpoint, as it is heavily dependent on cardiopulmonary reserve and can be affected by conditions unrelated to IBM. Also, bimagrumab may have an effect on muscle mass but does not affect inflammation and cell stress, and therefore muscle function may remain impaired.

\section{Oxandrolone}

Oxandrolone is a synthetic androgen and an anabolic steroid which has a myotrophic effect [50]. A trial was performed on 19 IBM patients, using a double-blind, placebo-controlled crossover study [20]. Patients were given oxandrolone or placebo for 12 weeks, then a 2-month washout, and crossover to the other treatment for 12 weeks. The primary outcome measure was whole body MVICT, with secondary outcome measures being whole body MMT, physical function testing, upper/lower extremity MMT and MVICT, and serology. No significant difference was seen between the groups calculating the generalized estimating equation (GEE) for whole body MVICT or MMT, however whole body MVICT nearly reached significance (median increase $15.5 \mathrm{~kg}$, GEE of treatment effect $1.27 \pm$ SE0.68, $p=0.061$ ). Upper extremity MVICT alone showed a significant mean increase of 1.45 GEE points ( \pm standard error $0.53 ; p$ $=0.006)$. This significant result was not replicated in upper extremity MMT, with a treatment effect of $0.74 \mathrm{MRC}$ points $( \pm$ SE0.57; $p=0.20)$. Both lower extremity MVICT and MMT did not show significant improvement. The reason for different outcomes between the upper and lower limbs is unclear. No further trials of oxandrolone in IBM have been reported.

\section{Exercise}

The effect of exercise programs has also been assessed in IBM following historical concerns that exercise could be harmful in patients with myositis, presumably due to findings of myalgia, raised $\mathrm{CK}$ and focal endomysial inflammation post-exertion [51]. A small unblinded study investigated a 12 week progressive resistance training program in five IBM patients. No significant difference was observed in mean MRC score, serum total CK, circulating lymphocytes or inflammation post-exercise program. The only positive results were significant increases in peak muscle strength when assessed using variable resistance exercise machines, most marked on knee extension (right leg press 39\% improvement \pm SE 12, left leg press $42 \%$ improvement $\pm 14, p<0.05$ for both) [19].

A further small open study assessed a 12-week aerobic, resistance and stretching exercise programme in seven IBM patients [21]. A significant increase in peak oxygen uptake $\left(\mathrm{VO}_{2} \max \right)($ mean $1.5 \mathrm{~L} / \mathrm{min} \pm \mathrm{SE} 0.2$ before the 
programme to $2.1 \mathrm{~L} / \mathrm{min} \pm 0.3$ after, $p<0.05)$ was observed, as well as mean strength on hip abduction (16.6\%), shoulder abduction (39.8\%), hip flexion $(35.6 \%)$, and knee flexion $(10.5 \%$, all $p<0.05)$ post-exercise programme. Some findings were replicated in a prospective randomized single-blinded crossover trial [26], where 17 IBM participants undertook a 12-week aerobic exercise programme, showing a large increase in $\mathrm{VO}_{2} \max (1.72$ on Cohen $d$ analysis \pm SD 0.28 , and 1.68 on Hedges $g$ analysis \pm SD 0.42).

An unblinded randomised control trial was performed in IBM assessing a 12-week blood-flow restricted (BFR) exercise programme against a non-exercise control group [25]. BFR involves partially inflating a cuff around a limb to restrict blood flow, then performing exercise at low loads. No improvement was noted in the Short Form Health Survey physical function domain, the primary outcome measure, although a significant decrease in knee extensor strength from baseline was seen in controls $(-9.2 \%$ change, $p=0.023)$, not seen in the BFR exercise group $(+0.9 \%$ change, $p=0.87)$. This lack of progression in the BFR exercise group may also reflect a protective effect of exercise, although the decrease in power in control does appear faster than would be expected from natural history studies [52].

These studies confirm that exercise is safe in IBM patients, with objective improvements in strength being demonstrated. No improvement in mobility has been shown. However, as exercise has many physical and psychological benefits, most clinicians would refer to a physiotherapist for an exercise programme or recommend that patients with IBM regularly take part in moderate physical activity.

\section{Other interventions}

Follistatin is a glycoprotein which binds to myostatin and prevents it from binding to activin IIB, thus preventing inhibition of myogenesis [53]. Myostatin knockout mice overexpressing full length follistatin have much greater muscle than control mice [54], thus an alternatively spliced isoform of the FST gene was developed for gene therapy using an adeno-associated virus 1 (AAV1) vector. The safety and efficacy of follistatin gene therapy was assessed in an unblinded trial with six IBM patients compared to natural history data from eight patients [24]. There was significant improvement in $6 \mathrm{MWD}$ for the treated group compared to a decrease in the untreated group $(+62.5 \mathrm{~m}$ versus $-33.0 \mathrm{~m}, p=$ 0.01 ), and muscle biopsies pre- and post-gene therapy suggested histopathological improvement. Whilst these results appear encouraging, there were confounders; the study was not blinded, and there were additional interventions, e.g. prednisolone and an exercise regime in the treatment group, which may have improved the 6MWD. In addition, the group used an annualised 6MWD, so that if a participant dropped out early the 12-month outcome was extrapolated from the last recorded time point, potentially contributing to further error. Overall it is not possible to attribute benefits to follistatin gene therapy from this study.

In addition to lowering cholesterol, statins have other actions including inhibition of inflammatory responses. Simvastatin was assessed in IBM a pilot study [22], where the primary outcome measures were those set by IMACS [55], including MMT and also IBMFRS [56]. None of the treated patients improved or worsened according to the IMACS criteria, and there was no improvement on MRI studies or muscle biopsies. 
The future of IBM clinical trials

The experience and outcome of clinical trials in IBM to date clearly indicates a pressing need for the discovery of future efficacious therapies.

\section{Choosing the right target}

The pendulum has swung between degenerative and autoimmune hypotheses with regard to the aetiopathogenesis of IBM [57]. There is mounting evidence emphasising the importance of autoimmune T cell-mediated mechanisms [58]. Clones of cytotoxic KLRG1 expressing T cells meeting criteria for T cell large granulocytic leukaemia have been demonstrated in IBM [38]. This discovery potentially explains resistance to conventional immunosuppression and raises the possibility for novel therapies targeting receptors on these cell populations [59]. The debate regarding the relative importance of degenerative processes such as protein dyshomeostasis and impaired autophagy is ongoing. It is clear that further work is required to better understand the aetiopathogenesis of IBM and facilitate discovery of targeted therapeutic interventions.

\section{Implementing a stratified approach}

Heterogeneity within IBM is increasingly being recognised and may relate to anti-CN-1A autoantibody status $[60,61]$. Other predictors of disease severity and progression are likely to be identified. Recently, our group showed that the long-term trajectory of IBM varies, and patients can be stratified by rate of dynamometry-measured strength loss (see Fig. 1 [52]). Such variability in progression may affect response to treatment and reduce sensitivity to detect change. Furthermore, patients with end-stage disease, where muscle has been extensively replaced by fatty tissue, will not respond to even the most efficacious systemic treatment. This issue has been compounded in the past by the use of diagnostic criteria for IBM which necessitated the presence of end stage disease features. Patients with shorter disease duration should be targeted for trial inclusion and thus techniques for facilitating earlier diagnosis of IBM pursued.

\section{Using sensitive and clinically relevant outcome measures}

Early clinical trials in IBM assessed strength manually using outcomes such as composite MMT and MVICT scores. More recent IBM studies have used QMT, particularly of finger flexors and quadriceps, muscles particularly affected in this condition, but these measures are technically difficult to perform and can exhibit high levels of variability. The 6MWD is a commonly used outcome measure in clinical trials, but is influenced significantly by cardiorespiratory fitness and lacks relevance in IBM. Alternative measures such as the timed up and go (TUG) test may be more appropriate [62].

Functional scoring tools including the IBMFRS [56] or sIFA [47] are focussed towards deficits seen in IBM, with the former used as the primary outcome in the pending arimoclomol study [45]. However, deficiencies in these tools are apparent, particularly with regard to assessment of hand function. There have been several attempts to create optimized tools which will require additional validation $[63,64]$. 

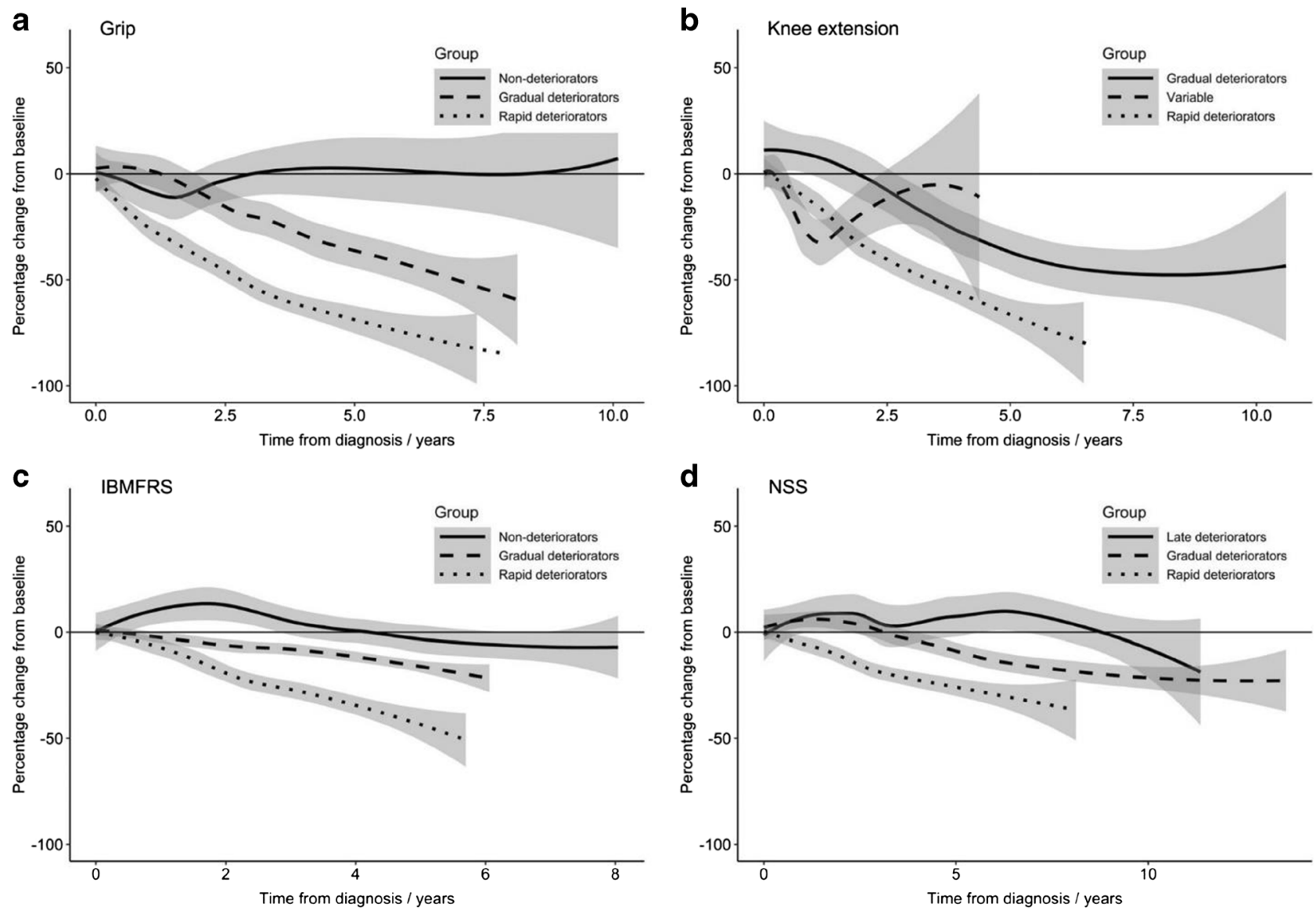

Fig. 1. Longitudinal trajectories of grip (a) and knee extension (b) strength, IBM-FRS (c) and NSS (d). Figure from Oldroyd et al. Long-term strength and functional status in inclusion body myositis and identification of trajectory subgroups. Muscle Nerve 62, 76-82 (2020). Reprinted under Creative Commons License 4.0

The development of objective and more sensitive radiological and blood biomarkers of IBM disease activity may be better tolerated, could identify earlier response signals, and shorten required clinical trial duration. Thigh muscle fat fraction can be determined by MRI which correlates well with the lower limb component of IBMFRS [65]. Lean body mass as determined by DEXA has also been performed $[27 \bullet \bullet]$. Overall, such techniques require further validation.

\section{Conclusion}

To date, clinical trials in IBM have not shown definitive benefits. Ineffective or poorly targeted treatments and issues with trial design may be contributory. Ideally, future IBM studies should be double-blind, placebo-controlled in nature, using sensitive, IBM-specific outcome measures. Trial design should also be stratified to account for disease heterogeneity. There is a risk that potentially efficacious therapies have been previously dismissed due to poor trial design. Opinion is swinging back towards considering immune-based treatments for IBM, and previous interventions may be revisited. 


\section{Funding}

HC is supported by the NIHR Manchester Biomedical Research Centre Funding Scheme. JBL holds a NIHR Clinical Lectureship in Neurology (NWN/006/025/A).

\section{Compliance with ethics guidelines}

\section{Conflict of interest}

Andrew Snedden declares no conflict of interest.

James B. Lilleker has undertaken consultancy work for Roche and received speakers' bureau from Sanofi Genzyme, outside the submitted work.

Hector Chinoy has undertaken consultancy work for Orphazyme, outside the submitted work.

Human and animal rights and informed consent

This article does not contain any studies with human or animal subjects performed by any of the authors.

\section{Disclaimer}

The views expressed in this publication are those of the authors and not necessarily those of the NHS, the National Institute for Health Research or the Department of Health.

Open Access This article is licensed under a Creative Commons Attribution 4.0 International License, which permits use, sharing, adaptation, distribution and reproduction in any medium or format, as long as you give appropriate credit to the original author(s) and the source, provide a link to the Creative Commons licence, and indicate if changes were made. The images or other third party material in this article are included in the article's Creative Commons licence, unless indicated otherwise in a credit line to the material. If material is not included in the article's Creative Commons licence and your intended use is not permitted by statutory regulation or exceeds the permitted use, you will need to obtain permission directly from the copyright holder. To view a copy of this licence, visit http://creativecommons.org/licenses/by/4.0/.

\section{References and recommended reading}

Papers of particular interest, published recently, have been highlighted as:

- Of importance

$\bullet \quad$ Of major importance

1. Griggs RC, Askanas V, DiMauro S, Engel A, Karpati G Mendell JR, et al. Inclusion body myositis and myopathies. Ann Neurol. 1995;38:705-13. https://doi.org/ 10.1002/ana.410380504.

2. Leff RL, Miller FW, Hicks J, Fraser DD, Plotz PH. The treatment of inclusion body myositis: a retrospective review and a randomized, prospective trial of immunosuppressive therapy. Medicine (Baltimore). 1993;72:225-35. https://doi.org/10.1097/00005792199307000-00002.

3. Soueidan SA, Dalakas MC. Treatment of inclusionbody myositis with high-dose intravenous immunoglobulin. Neurology. 1993;43:876-6. https://doi.org/ 10.1212/WNL.43.5.876.

4. Joffe MM, Love LA, Leff RL, Fraser DD, Targoff IN, Hicks JE, et al. Drug therapy of the idiopathic inflammatory myopathies: predictors of response to prednisone, azathioprine, and methotrexate and a comparison of their efficacy. Am J Med. 1993;94:379-87. https://doi.org/10.1016/0002-9343(93)90148-I. 
5. Amato AA, Barohn RJ, Jackson CE, Pappert EJ, Sahenk Z, Kissel JT. Inclusion body myositis: treatment with intravenous immunoglobulin. Neurology.

1994;44:1516-8. https://doi.org/10.1212/wnl.44.8. 1516.

6. Dalakas MC, Sonies B, Dambrosia J, Sekul E, Cupler E, Sivakumar K. Treatment of inclusion-body myositis with IVIg: a double-blind, placebo- controlled study. Neurology. 1997;48:712-6. https://doi.org/10.1212/ WNL.48.3.712.

7. Mastaglia FL. Immunoglobulin therapy in inflammatory myopathies. J Neurol Neurosurg Psychiatry. 1998;65:107-10. https://doi.org/10.1136/jnnp.65.1. 107.

8. Walter MC, Lochmüller H, Toepfer M, Schlotter B, Reilich P, Schröder M, et al. High-dose immunoglobulin therapy in sporadic inclusion body myositis: a double-blind, placebo-controlled study. J Neurol. 2000;247:22-8. https://doi.org/10.1007/ s004150050005.

9. Dalakas MC, Koffman B, Fujii M, Spector S, Sivakumar $\mathrm{K}$, Cupler E. A controlled study of intravenous immunoglobulin combined with prednisone in the treatment of IBM. Neurology. 2001;56:323-7. https://doi. org/10.1212/wnl.56.3.323.

10. Tawil R. Randomized pilot trial of INF1a (Avonex) in patients with inclusion body myositis. Neurology. 2001;57:1566-70. https://doi.org/10.1212/WNL.57.9. 1566.

11. Badrising UA, Maat-Schieman MLC, Ferrari MD, Zwinderman AH, Wessels JAM, Breedveld FC, et al. Comparison of weakness progression in inclusion body myositis during treatment with methotrexate or placebo. Ann Neurol. 2002;51:369-72. https://doi. org/10.1002/ana.10121.

12. Lindberg C, Trysberg E, Tarkowski A, Oldfors A. Anti-Tlymphocyte globulin treatment in inclusion body myositis: a randomized pilot study. Neurology. 2003;61:260-2. https://doi.org/10.1212/01.WNL. 0000071852.27182.C7. Significant improvement in overall muscle power on myometry in combined methotrexate/ATG group compared to methotrexate group in this unblinded study. No significant differences in muscle biopsy.

13. The Muscle Study Group. Randomized pilot trial of high-dose INF-1a in patients with inclusion body myositis. Neurology. 2004;63:718-20. https://doi.org/ 10.1212/01.WNL.0000134675.98525.79.

14. Barohn RJ, Herbelin L, Kissel JT, King W, McVey AL, Saperstein DS, et al. Pilot trial of etanercept in the treatment of inclusion-body myositis. Neurology, vol. 66, 2006. https://doi.org/10.1212/01.wnl.

0000192258.32408 .54 .
15.• Dastmalchi M, Grundtman C, Alexanderson H, Mavragani CP, Einarsdottir H, Helmers SB, et al. A high incidence of disease flares in an open pilot study of infliximab in patients with refractory inflammatory myopathies. Ann Rheum Dis. 2008;67:1670-7. https://doi.org/10.1136/ard.2007.077974. A small study, but extensive assessment of inflammatory marker expression in muscle and blood. Results suggested that Infliximab may exacerbate IIM.

16. Dalakas MC, Rakocevic G, Schmidt J, Salajegheh M, McElroy B, Harris-Love MO, et al. Effect of alemtuzumab (CAMPATH 1-H) in patients with inclusion-body myositis. Brain. 2009;132:1536-44. https://doi.org/10.1093/brain/awp104.

17. Kosmidis ML, Alexopoulos H, Tzioufas AG, Dalakas MC. The effect of anakinra, an IL1 receptor antagonist, in patients with sporadic inclusion body myositis (sIBM): a small pilot study. J Neurol Sci. 2013;334:123-5. https://doi.org/10.1016/j.jns.2013. 08.007.

18.• Benveniste O, Hogrel J-Y, Belin L, Annoussamy M, Bachasson D, Rigolet A, et al. Sirolimus for treatment of patients with inclusion body myositis: a randomised, double-blind, placebo-controlled, proof-of-concept, phase 2b trial. Lancet Rheumatol. 2020. https://doi. org/10.1016/S2665-9913(20)30280-0. Newest trial of immunosuppression in IBM. Improvement in 6MWD, HAQ-DI, forced vital capacity, and thigh fat fraction but not in isometric quadriceps strength, which is the primary outcome measure.

19. Spector SA, Lemmer JT, Koffman BM, Fleisher TA, Feuerstein IM, Hurley BF, et al. Safety and efficacy of strength training in patients with sporadic inclusion body myositis. Muscle and Nerve 1997;20:1242-8. 10.1002/(SICI)1097-4598(199710)20:10<1242::AIDMUS6>3.0.CO;2-C.

20. Rutkove SB, Parker RA, Nardin RA, Connolly CE, Felice $\mathrm{KJ}$, Raynor EM. A pilot randomized trial of oxandrolone in inclusion body myositis. Neurology. 2002;58:1081-7. https://doi.org/10.1212/WNL.58.7. 1081.

21. Johnson LG, Collier KE, Edwards DJ, Philippe DL, Eastwood PR, Walters SE, et al. Improvement in aerobic capacity after an exercise program in sporadic inclusion body myositis. J Clin Neuromuscul Dis. 2009;10:178-84. https://doi.org/10.1097/CND. 0b013e3181a23c86.

22. Sancricca C, Mora M, Ricci E, Tonali PA, Mantegazza R, Mirabella M. Pilot trial of simvastatin in the treatment of sporadic inclusion-body myositis. Neurol Sci. 2011;32:841-7. https://doi.org/10.1007/s10072-0110657-6. 
23.• Ahmed M, Machado PM, Miller A, Spicer C, Herbelin $\mathrm{L}, \mathrm{He}$ J, et al. Targeting protein homeostasis in sporadic inclusion body myositis. Sci Transl Med.

2016;8:331ra41-1. https://doi.org/10.1126/ scitranslmed.aad4583. Interesting mix of in vitro, animal and human trials of arimoclomol.

24. Mendell JR, Sahenk Z, Al-Zaidy S, Rodino-Klapac LR, Lowes LP, Alfano LN, et al. Follistatin gene therapy for sporadic inclusion body myositis improves functional outcomes. Mol Ther. 2017;25:870-9. https://doi.org/ 10.1016/j.ymthe.2017.02.015.

25. Jørgensen A, Aagaard P, Frandsen U, Boyle E, Diederichsen L. Blood-flow restricted resistance training in patients with sporadic inclusion body myositis: a randomized controlled trial. Scand J Rheumatol. 2018;47:400-9. https://doi.org/10.1080/03009742. 2017.1423109.

26. Wallace A, Pietrusz A, Dewar E, Dudziec M, Jones K, Hennis $\mathrm{P}$, et al. Community exercise is feasible for neuromuscular diseases and can improve aerobic capacity. Neurology. 2019;92:e1773-85. https://doi.org/ 10.1212/WNL.0000000000007265.

27.• Hanna MG, Badrising UA, Benveniste O, Lloyd TE, Needham M, Chinoy H, et al. Safety and efficacy of intravenous bimagrumab in inclusion body myositis (RESILIENT): a randomised, double-blind, placebocontrolled phase 2b trial. Lancet Neurol. 2019;18:83444. https://doi.org/10.1016/S1474-4422(19)30200-5 Very large, well controlled trial. No change in primary outcome measure (6MWD), but some significant improvement in secondary outcome measures.

28. Whitaker JN. Inflammatory myopathy: a review of etiologic and pathogenetic factors. Muscle Nerve. 1982;5:573-92. https://doi.org/10.1002/mus. 880050802 .

29. Bohan A, Peter JB. Polymyositis and dermatomyositis (second of two parts). N Engl J Med. 1975;292:403-7. https://doi.org/10.1056/NEJM197502202920807.

30. Kalliolias GD, Ivashkiv LB. TNF biology, pathogenic mechanisms and emerging therapeutic strategies. Nat Rev Rheumatol. 2016;12:49-62. https://doi.org/10. 1038/nrrheum.2015.169.

31. Weinblatt ME, Kremer JM, Bankhurst AD, Bulpitt KJ, Fleischmann RM, Fox RI, et al. A trial of etanercept, a recombinant tumor necrosis factor receptor:Fc fusion protein, in patients with rheumatoid arthritis receiving methotrexate. N Engl J Med. 1999;340:253-9. https:// doi.org/10.1056/NEJM199901283400401.

32. Josefson A, Romanus E. Carlsson J. A functional index in myositis. J Rheumatol. 1996;23:1380-4.

33. Isenberg DA, Allen E, Farewell V, Ehrenstein MR, Hanna MG, Lundberg IE, et al. International consensus outcome measures for patients with idiopathic inflammatory myopathies. Development and initial validation of myositis activity and damage indices in patients with adult onset disease. Rheumatology. 2004;43:49-54. https://doi.org/10.1093/ rheumatology $/ \operatorname{keg} 427$.
34. Schmidt J, Barthel K, Wrede A, Salajegheh M, Bähr M, Dalakas MC. Interrelation of inflammation and APP in sIBM: IL-1 $\beta$ induces accumulation of $\beta$-amyloid in skeletal muscle. Brain. 2008;131:1228-40. https://doi. org/10.1093/brain/awn053.

35. Cavalli G, Dinarello CA. Anakinra therapy for noncancer inflammatory diseases. Front Pharmacol. 2018;9. https://doi.org/10.3389/fphar.2018.01157.

36. Warner JL, Arnason JE. Alemtuzumab use in relapsed and refractory chronic lymphocytic leukemia: a history and discussion of future rational use. Ther Adv Hematol. 2012;3:375-89. https://doi.org/10.1177/ 2040620712458949.

37. Willis MD, Robertson NP. Alemtuzumab for Multiple Sclerosis. Curr Neurol Neurosci Rep. 2016;16:84. https://doi.org/10.1007/s11910-016-0685-y.

38. Greenberg SA, Pinkus JL, Kong SW, Baecher-Allan C, Amato AA, Dorfman DM. Highly differentiated cytotoxic T cells in inclusion body myositis. Brain. 2019;142:2590-604. https://doi.org/10.1093/brain/ awz207.

39. Zaza G, Granata S, Caletti C, Signorini L, Stallone G, Lupo A. mTOR Inhibition role in cellular mechanisms. Transplantation. 2018;102:S3-16. https://doi.org/10. 1097/TP.0000000000001806.

40. Ikenaga C, Kubota A, Kadoya M, Taira K, Uchio N, Hida A, et al. Clinicopathologic features of myositis patients with CD8-MHC-1 complex pathology. Neurology. 2017;89:1060-8. https://doi.org/10.1212/ WNL.0000000000004333.

41. Horvath R, Fu K, Johns T, Genge A, Karpati G, Shoubridge EA. Characterization of the mitochondrial DNA abnormalities in the skeletal muscle of patients with inclusion body myositis. J Neuropathol Exp Neurol. 1998;57:396-403. https://doi.org/10.1097/ 00005072-199805000-00003.

42. Cacciottolo M, Nogalska A, D'Agostino C, Engel WK, Askanas V. Chaperone-mediated autophagy components are upregulated in sporadic inclusion-body myositis muscle fibres. Neuropathol Appl Neurobiol. 2013;39:750-61. https://doi.org/10.1111/nan.12038.

43. Askanas V, Engel WK, Nogalska A. Sporadic inclusionbody myositis: A degenerative muscle disease associated with aging, impaired muscle protein homeostasis and abnormal mitophagy. Biochim Biophys Acta - Mol Basis Dis. 2015;1852:633-43. https://doi.org/10. 1016/j.bbadis.2014.09.005.

44. Rakonczay Z, Iványi B, Varga I, Boros I, Jednákovits A, Németh I, et al. Nontoxic heat shock protein coinducer BRX-220 protects against acute pancreatitis in rats. Free Radic Biol Med. 2002;32:1283-92. https://doi.org/10. 1016/S0891-5849(02)00833-X.

45. Orphazyme. Study of Arimoclomol in Inclusion Body Myositis (IBM) NCT02753530. ClinicaltrialsGov n.d. https://clinicaltrials.gov/ct2/show/NCT02753530? term $=02753530$ \&draw $=2$ \&rank $=1$ (accessed October 9, 2020).

46. Lach-Trifilieff E, Minetti GC, Sheppard K, Ibebunjo C, Feige JN, Hartmann S, et al. An antibody blocking 
activin type II receptors induces strong skeletal muscle hypertrophy and protects from atrophy. Mol Cell Biol. 2014;34:606-18. https://doi.org/10.1128/mcb.0130713.

47. DeMuro C, Lewis S, Lowes L, Alfano L, Tseng B, Gnanasakthy A. Development of the sporadic inclusion body myositis physical functioning assessment. Muscle and Nerve. 2016;54:653-7. https://doi.org/10 1002/mus.25079.

48. Amato AA, Sivakumar K, Goyal N, David WS, Salajegheh M, Praestgaard J, et al. Treatment of sporadic inclusion body myositis with bimagrumab. Neurology. 2014;83:2239-46. https://doi.org/10. 1212/wnl.0000000000001070.

49. Schmidt J. Endpoint choice for inclusion body myositis: a step too far? Lancet Neurol. 2019;18:807-8. https://doi.org/10.1016/S1474-4422(19)30279-0.

50. Sheffield-Moore M, Urban RJ, Wolf SE, Jiang J, Catlin DH, Herndon DN, et al. Short-term oxandrolone administration stimulates net muscle protein synthesis in young men. J Clin Endocrinol Metab. 1999;84:270511. https://doi.org/10.1210/jcem.84.8.5923.

51. Fielding RA, Manfredi TJ, Ding W, Fiatarone MA, Evans WJ, Cannon JG. Acute phase response in exercise. III. Neutrophil and IL-1 beta accumulation in skeletal muscle. Am J Physiol Integr Comp Physiol.

1993;265:R166-72. https://doi.org/10.1152/ajpregu. 1993.265.1.R166.

52. Oldroyd AGS, Lilleker JB, Williams J, Chinoy H, Miller JAL. Long-term strength and functional status in inclusion body myositis and identification of trajectory subgroups. Muscle Nerve. 2020;62:76-82. https://doi. org/10.1002/mus.26859.

53. Amthor H, Nicholas G, McKinnell I, Kemp CF, Sharma M, Kambadur R, et al. Follistatin complexes Myostatin and antagonises Myostatin-mediated inhibition of myogenesis. Dev Biol. 2004;270:19-30. https://doi. org/10.1016/j.ydbio.2004.01.046.

54. Lee SJ, McPherron AC. Regulation of myostatin activity and muscle growth. Proc Natl Acad Sci U S A. 2001;98:9306-11. https://doi.org/10.1073/pnas. 151270098.

55. Miller FW, Rider LG, Chung YL, Cooper R, Danko K, Farewell V, et al. Proposed preliminary core set measures for disease outcome assessment in adult and juvenile idiopathic inflammatory myopathies. Rheumatology (Oxford). 2001;40:1262-73. https://doi. org/10.1093/rheumatology/40.11.1262.

56. Jackson CE, Barohn RJ, Gronseth G, Pandya S, Herbelin $\mathrm{L}$, Tawil $\mathrm{R}$, et al. Inclusion body myositis functional rating scale: a reliable and valid measure of disease severity. Muscle and Nerve. 2008;37:473-6. https:// doi.org/10.1002/mus.20958.

57. Benveniste O, Stenzel W, Hilton-Jones D, Sandri M, Boyer O, van Engelen BGM. Amyloid deposits and inflammatory infiltrates in sporadic inclusion body myositis: the inflammatory egg comes before the degenerative chicken. Acta Neuropathol. 2015;129:61124. https://doi.org/10.1007/s00401-015-1384-5.

58. Greenberg SA. Inclusion body myositis: clinical features and pathogenesis. Nat Rev Rheumatol. 2019;15:257-72. https://doi.org/10.1038/s41584019-0186-X.

59. Greenberg SA, Gulla S, Thompson K. KLRG1 Depletion Therapy- US Patent number 16/327576. 16/327576, 2019.

60. Lilleker JB, Rietveld A, Pye SR, Mariampillai K, Benveniste O, Peeters MTJ, et al. Cytosolic 5'-nucleotidase $1 \mathrm{~A}$ autoantibody profile and clinical characteristics in inclusion body myositis. Ann Rheum Dis. 2017;76:862-8. https://doi.org/10.1136/ annrheumdis-2016-210282.

61. Goyal NA, Cash TM, Alam U, Enam S, Tierney P, Araujo N, et al. Seropositivity for NT5c1A antibody in sporadic inclusion body myositis predicts more severe motor, bulbar and respiratory involvement n.d. https://doi.org/10.1136/jnnp-2014-310008.

62. Jørgensen AN, Aagaard P, Nielsen JL, Christiansen M, Hvid LG, Frandsen U, et al. Physical function and muscle strength in sporadic inclusion body myositis. Muscle Nerve. 2017;56:E50-8. https://doi.org/10. 1002/mus.25603.

63. Lin AY, Siener CS, Faino AV, Seiffert M, Weihl CC, Wang LH. Optimizing hand-function patient outcome measures for inclusion body myositis. Neuromuscul Disord. 2020;30:807-14. https://doi.org/10.1016/j. nmd.2020.08.358.

64. Ramdharry G, Morrow J, Hudgens S, Skorupinska I, Gwathmey K, Currence M, et al. Investigation of the psychometric properties of the inclusion body myositis functional rating scale with rasch analysis. Muscle Nerve. 2019;60:161-8. https://doi.org/10.1002/mus. 26521.

65. Morrow JM, Sinclair CDJ, Fischmann A, Machado PM, Reilly MM, Yousry TA, et al. MRI biomarker assessment of neuromuscular disease progression: a prospective observational cohort study. Lancet Neurol. 2016;15:65-77. https://doi.org/10.1016/S14744422(15)00242-2.

\section{Publisher's Note}

Springer Nature remains neutral with regard to jurisdictional claims in published maps and institutional affiliations. 